\title{
Reconstruction and quantitative evaluation of dopaminergic innervation of striatal neurons in dissociated primary cultures
}

\section{$\operatorname{AUTHOR}(\mathrm{S}):$}

Wakita, Seiko; Izumi, Yasuhiko; Matsuo, Takaaki; Kume, Toshiaki; Takada-Takatori, Yuki; Sawada, Hideyuki; Akaike, Akinori

\section{CITATION:}

Wakita, Seiko ...[et al]. Reconstruction and quantitative evaluation of dopaminergic innervation of striatal neurons in dissociated primary cultures. Journal of neuroscience methods 2010, 192(1): 83-89

\section{ISSUE DATE:}

2010-09-30

URL:

http://hdl.handle.net/2433/126833

\section{RIGHT:}

(c) 2010 Elsevier B.V.; この論文は出版社版でありません。引用の際には 出版社版をご確認ご利用ください。; This is not the published version. Please cite only the published version. 


\section{Reconstruction and quantitative evaluation of dopaminergic innervation of striatal neurons in dissociated primary cultures}

Seiko Wakita ${ }^{1}$, Yasuhiko Izumi ${ }^{1}$, Takaaki Matsuo ${ }^{1}$, Toshiaki Kume ${ }^{1}$, Yuki Takada-Takatori ${ }^{2}$,

Hideyuki Sawada $^{3}$ and Akinori Akaike ${ }^{1}$

${ }^{1}$ Department of Pharmacology, Graduate School of Pharmaceutical Sciences, Kyoto University,

46-29 Yoshida-shimoadachi-cho, Sakyo-ku, Kyoto 606-8501, Japan

${ }^{2}$ Department of Pharmacology, Faculty of Pharmaceutical Sciences, Doshisha Women's College,

Kodo, Kyotanabe, Kyoto 610-0395, Japan

${ }^{3}$ Department of Neurology and Clinical Research Center, Center for Neurological Diseases, Utano

National Hospital,

8 Ondoyama-cho, Narutaki, Ukyo-ku, Kyoto, 616-5152, Japan

Abbreviated title: A simple system for evaluating neural projections 


\section{Address correspondence to:}

Akinori Akaike, Ph.D.

Department of Pharmacology, Graduate School of Pharmaceutical Sciences, Kyoto University,

46-29 Yoshida-shimoadachi-cho, Sakyo-ku, Kyoto 606-8501, Japan,

Tel: +81-75-753-4550, Fax: +81-75-753-4579;

E-mail: aakaike@ pharm.kyoto-u.ac.jp

Number of text pages: 27

Number of figures: 6

Type of article: Research Paper 


\section{Research highlights}

- Mesencephalic and striatal cell regions are adjacently formed in dissociated cultures.

- Dopaminergic neurites preferentially extend to the striatal cell region.

- Dopaminergic neurites form synapses in the striatal cell region.

- Evaluation system for dopaminergic projection is established using dissociated cells. 


\section{Abstract}

Repairing the nigrostriatal pathway is expected to become a future treatment strategy for

Parkinson disease. Our aim is to establish an in vitro model for the quantitative analysis of the

nigrostriatal projections of dopaminergic neurons using primary dissociated neruons. To form the mesencephalic cell region, mesencephalic cells derived from rat embryos were plated within an isolation wall, which was removed after cell adhesion to the coverslip. After incubation for 11 days, the dopaminergic neurites extending to the outside of the mesencephalic cell region were mainly axons. Treatment with glial cell line-derived neurotrophic factor for 11 days significantly promoted the outgrowth of dopaminergic axons from the mesencephalic cell region in a concentration-dependent manner. When striatal cells were plated outside the mesencephalic cell region, dopaminergic neurites were remarkably extended to the striatal cell region. Moreover, immunocytochemistry for tyrosine hydroxylase and synaptophysin revealed that dopaminergic axons formed synapses with striatal neurons. By contrast, spinal cells did not increase dopaminergic neurite outgrowth. These results indicate that the present method is valuable for evaluating nigrostriatal projections in vitro.

KEYWORDS: dopaminergic neurite growth, glial cell line-derived neurotrophic factor, nigro-striatal projection, Parkinson disease 


\section{Abbreviations:}

GAP43, growth-associated protein-43; DIV, days in vitro; GDNF, glial cell line-derived

neurotrophic factor; GIRK-2, G-protein-activated inwardly rectifying potassium channel 2; MAP2, microtubule-associated protein 2; pNF, phosphorylated neurofilaments; St, Striatal; Sp, Spinal; TH, tyrosine hydroxylase. 


\section{Introduction}

The main pathological feature of Parkinson disease is a selective degeneration of dopaminergic neurons in the substantia nigra. Since the dopaminergic neurons in the nigrostriatal pathway play a central role in the regulation of motor functions, the progressive degeneration causes movement disorders, such as tremors, akinesia and rigidity. Although a means for repairing the nigrostriatal pathway has been desired for decades, there is no successful therapeutic strategy and further optimization is necessary.

Several factors that influence dopaminergic axonal projections to the striatum, such as semaphorins (3A, 3C and 3F) and ephrin-A/B, have been identified (Yue et al., 1999; Cooper et al., 2009; Hernandes-Montiel et al., 2008). When an explant from the midbrain was cultured adjacent to an explant from the striatum, dopaminergic axons were attracted to the striatal explant (Hernandes-Montiel et al., 2008). Dopaminergic projections have also been replicated through contact between cultured slices of the ventral mesencephalon and the striatum (Maeda et al., 1998; Katsuki et al., 2001). Østergaard et al. (1996) and Hernandes-Montiel et al. (2008) evaluated the dopaminergic fiber innervations of striatal cultures by a scoring method. However, considerable effort (e.g., a large sample size) is required for a qualitative analysis. Flat whole-mount preparations of embryonic brain can mimic the development of dopaminergic axons in vivo (Nakamura et al., 2000), although this technique is also unsuitable for the rapid screening of large numbers of 
chemicals for their effects on neurite outgrowth. Therefore, we focused on developing a simple quantitative system for assessing dopaminergic neurite outgrowth and neural projections to the striatum. Primary neuronal cultures are easily prepared and suitable for the analysis of cellular mechanisms. However, to our knowledge, there have been no reports of neuronal projections using primary cultures consisting of dissociated cells.

Glial cell line-derived neurotrophic factor (GDNF), a member of the transforming growth factor superfamily, is suggested as a specific neurotrophic factor for midbrain dopaminergic neurons (Lin et al., 1993). Overexpression of GDNF in the striatum enhanced fiber outgrowth of fetal ventral mesencephalic grafts from the substantia nigra to the striatum (Redmond et al., 2009) and recovered functional impairment induced by 6-OHDA (Kirik et al., 2000; Thompson et al., 2009; Gaillard et $a l ., 2009)$. These observations raise the possibility that GDNF is involved in extending dopaminergic projections to the striatum. In this study, we used GDNF as a positive control for dopaminergic axonal projections.

Herein, we developed a simple method of quantitatively evaluating the nigrostriatal projections of dopaminergic neurons with the use of primary dissociated neruons. Using this system, we found that dissociated dopaminergic neurons preferentially extended their axons to striatal cells and formed synapses with striatal neurons. 


\section{Materials and methods}

\subsection{Reagents}

Human glial derived neurotrophic factor (GDNF) was purchased from Almone Labs Ltd.

(Jerusalem, Israel). Press-to seal ${ }^{\mathrm{TM}}$ silicone sheets $(1.0 \mathrm{~mm}$ thick) were purchased from Invitrogene (Carlsbad, CA).

\subsection{Primary mesencephalic, striatal and spinal cultures}

Primary cultures were established according to methods described previously (Izumi et al.,

2009). In brief, the ventral mesencephalon, striatum and spinal cord were dissected from rat embryos

on the 14 th or 16th day of gestation. Dopaminergic neurons in the substantia nigra are born at

embryonic day 12 (E12), and their axons extend along the medial forebrain bundle at E13-14 and

begin to innervate the striatum from E16 during in vivo development (Gates et al., 2004.). Cultures

from E16 rats were used in this study unless otherwise noted. The isolated tissues were then

chemically and mechanically dissociated into single cell suspensions. For counting living cells in

cell suspension, we performed trypan blue exclusion method before plating. In the process of

preparation of the suspension, the cell survival rate was about a half. Viable cells were plated onto

$0.1 \%$ polyethyleneimine-coated plastic coverslips at a density of $3.0 \times 10^{5} \mathrm{cells} / \mathrm{cm}^{2}$ for mesencephalic

cells, $0.75-3.0 \times 10^{5}$ cells $/ \mathrm{cm}^{2}$ for striatal cells and $1.5-3.0 \times 10^{5} \mathrm{cells} / \mathrm{cm}^{2}$ for spinal cells. Cultures 
were maintained in Eagle's minimum essential medium containing $10 \%$ fetal calf serum [1-4 days in vitro (DIV)] or horse serum [5-12 DIV]. Cultures were incubated at $37^{\circ} \mathrm{C}$ in an atmosphere of $5 \%$ $\mathrm{CO}_{2}$ in air with $100 \%$ relative humidity. The animals were treated in accordance with the guidelines of the Kyoto University animal experimentation committee and of the Japanese Pharmacological Society.

\subsection{Formation of a mesencephalic cell region on coverslips}

Press-to seal $^{\mathrm{TM}}$ silicone sheets $(13 \mathrm{~cm} \times 18 \mathrm{~cm}, 1.0 \mathrm{~mm}$ thick $)$ were subdivided into rectangles, $11 \mathrm{~mm}$ long and $22 \mathrm{~mm}$ wide, with a size No.11 stainless steel surgical blade (Feather Safety Razor Co., Ltd., Osaka, Japan). The inside of each rectangle was cut out to make a well, 6 mm long and $14 \mathrm{~mm}$ wide.

The silicone isolation wall was placed on a polyethylenimine-coated coverslip in a $35 \mathrm{~mm}$ culture dish (Fig. 1A), and the preparation was sealed by pressing with a coverslip. Mesencephalic cell suspensions $(150 \mu \mathrm{L})$ derived from rat embryos were plated inside the isolation wall at a density of $3.0 \times 10^{5}$ cells $/ \mathrm{cm}^{2}$ (Fig. 1B). The isolation wall was removed $24 \mathrm{~h}$ after plating (Fig. 1C).

\subsection{Immunocytochemistry}

Primary cultures were fixed for immunocytochemistry at 12 DIV. Following fixation with 
$4 \%$ paraformaldehyde for $30 \mathrm{~min}$, they were incubated with $0.2 \%$ Triton X-100 for $15 \mathrm{~min}$. They were then incubated with a rabbit anti-tyrosine hydroxylase affinity-purified polyclonal antibody (1:400; TH; Millipore Corporation, Bedford, MA; Cat\# AB152) for $2 \mathrm{~h}$, with biotinylated anti-Rabbit IgG $(\mathrm{H}+\mathrm{L})$ (1:200; Vector Laboratories Inc. Burlingame, CA) for $1 \mathrm{~h}$ and with avidin-biotinylated horseradish peroxidase complex (Vector Laboratories Inc) for $1 \mathrm{~h}$ at $25^{\circ} \mathrm{C}$. Finally, they were reacted with a diaminobenzidine (Dojindo Laboratories, Kumamoto, Japan) solution for $8 \mathrm{~min}$. The survival rate of dopaminergic neurons in culture was gradually decreased to $40 \%$ until 5 DIV, but was not decreased after 5 DIV.

For immunofluorescence staining, primary cultures were incubated with anti-TH (Cat\# AB152 or 1:400; Sigma, St. Louis, MO; Cat\# M1409), anti-microtubule associated protein 2 (MAP2; 1:500; Sigma; Cat\# M1409), anti-neurofilament (phospho), (pNF; 1:1000; Covance, Emeryville, CA; Cat\# SMI-31R), anti-growth-associated protein-43 (GAP43; 1:500; Sigma; Cat\# G9264), or anti-synaptophysin (1:500; Millipore; Cat\# MAB5258) antibody for $2 \mathrm{~h}$, with Alexa Fluror 594 goat anti-rabbit IgG $(\mathrm{H}+\mathrm{L})$ or Alexa Fluror 488 goat anti-mouse $\operatorname{IgG}(\mathrm{H}+\mathrm{L})(1: 500$; Invitrogene; Cat\# A11012 and A11001) for $1 \mathrm{~h}$, and with Hoechst33258 (0.1 mg/mL; Calbiochem) for $15 \mathrm{~min}$. To reveal the dopamine neuronal subtypes, we performed double staining for TH and G-protein-activated inwardly rectifying potassium channel (GIRK)-2 (1:200; Alomone labs; Cat\# APC-006), a marker of dopaminergic neurons of the substantia nigra pars compacta, or calbindin 
(1:200; Sigma; Cat\# C8666), a maker of those of the ventral tegmental area..In this cultures, the percentage of dopaminergic neurons that express GIRK-2 and calbindin were 48 and $46 \%$, respectively.

\subsection{Measurement of dopaminergic neurite length}

The borderline of the mesencephalic cell region (dotted line) was defined as the position of the most laterally located dopaminergic soma (open arrowhead) (Fig. 1D). The distance from dopaminergic growth cones to the borderline (arrows) was measured and regarded as neurite length

(Fig. 1D). To make a continuous image, several photographs were merged with a BZ Analyzer

(KEYENCE, Osaka, Japan). Four continuous images whose widths were $890 \mu \mathrm{m}$ were obtained from a coverslip. The number of subjects for each experiment was 4 .

\subsection{Statistics}

The statistical significance of the differences between three or more groups was analyzed with a one-way ANOVA and post hoc multiple comparison using Tukey's test. Statistical significance was defined as $p<0.05$. Data are expressed as the mean $\pm \mathrm{SEM}$. 


\section{Results}

\section{1. Morphological features of dopaminergic neurites extending from the mesencephalic cell}

region

To investigate morphological features of dopaminergic neurites extending from the

mesencephalic cell region, mesencephalic cell cultures were processed for immunocytochemistry for

TH at 12 DIV (Fig. 2A). The distribution of dopaminergic growth cones from the borderline is

shown in Fig. 2B. As the distance from the borderline increased, the number of dopaminergic growth

cones decreased. Next, we determined whether the dopaminergic neurites extending from the

mesencephalic cell region were axons or dendrites. Fig. 2C-F shows fluorescence images of cells

immunostained with the antibody against MAP2 for dendrites, pNF for axons and GAP43 for axonal

growth cones. Although dopaminergic neurites near the soma were MAP2-immunoreactive, those

away from the borderline were pNF-immunoreactive. The dopaminergic neurites away from the

borderline were also stained with the anti-GAP43 antiboby. These findings suggest that the

dopaminergic neurites extending from the mesencephalic cell region are mainly axons.

\subsection{Quantitative evaluation of dopaminergic neurite outgrowth induced by GDNF}

GDNF is known to promote dopaminergic neurite outgrowth. To confirm the validity of the new system for evaluating dopaminergic neurite outgrowth, cultures were grown for 11 days in 
the presence of GDNF. Fig. 3A shows the typical dopaminergic neurite outgrowth induced by GDNF $(10 \mathrm{ng} / \mathrm{mL})$. The distribution of dopaminergic growth cones from the borderline revealed that longer dopaminergic neurites extended from the mesencephalic region in GDNF-treated cultures than in control cultures (Fig. 3B). To evaluate the neurite outgrowth quantitatively, the distance of growth cones from the borderline was regarded as dopaminergic neurite length, and the length of neurites were summed. Fig. $3 \mathrm{C}$ shows that GDNF enhanced dopaminergic neurite outgrowth in a concentration-dependent manner. In cultures from E14 rats, GDNF also enhanced dopaminergic neurite outgrowth in a concentration-dependent manner (Fig. 3D). Using immunocytochemistry, we ascertained that the dopaminergic neurites extending from the mesencephalic cell region in the presence of GDNF were also axons (data not shown).

\subsection{Paired-cultivation of mesencephalic cells and striatal or spinal cells}

To examine the projections of dopaminergic neurons, the striatal or spinal cell region was laid next to the mesencephalic cell region. After mesencephalic cells were plated within the silicone isolation wall, striatal cells or spinal cells were plated outside the wall at a density of $3.0 \times 10^{5}$ cells $/ \mathrm{cm}^{2}$ (Fig. 4A). When the isolation wall was removed at 2 DIV, separated regions of mesencephalic (M) cells and striatal (St) or spinal (Sp) cells had been formed (Fig. 4B and C). The distance between two-cell populations was $200 \mu \mathrm{m}$. 


\subsection{Preferential projection of dopaminergic neurites to striatal cells}

We next examined the effect of striatal cells on dopaminergic neurite outgrowth in the paired-cultures of mesencephalic and striatal cells. Fig. 5A shows the typical dopaminergic neurite outgrowth by striatal cells. Dopaminergic neurites extended along the cluster of striatal cells. Striatal cells increased the number of dopaminergic growth cones and promoted dopaminergic neurite outgrowth in a cell density-dependent manner (Fig. 5C and E). To examine whether dopaminergic neurites prefer to innervate striatal cells, mesencephalic cells were paired-cultured with spinal cells because the spinal cord does not receive dopaminergic innervation in vivo. Fig. 5B shows the typical dopaminergic neurite outgrowth by spinal cells. In contrast to striatal cells, spinal cells did not increase the number of growth cones or neurite length (Fig. 5D and F). Similar results were obtained from cultures from E14 rats (Fig. $\mathrm{G}$ and $\mathrm{H}$ ).

To examine whether dopaminergic axons formed synapses with striatal neruons,

paired-cultures of mesencephalic cells and striatal cells were processed for immunocytochemistry for TH and synaptophysin (presynaptic marker) at 12 DIV. Synaptophysin was co-immunostained with TH-positive dopaminergic axons in the striatal cell region (Fig. 6A-D). In addition, some, but not all, of dopaminergic axons extending to the striatal cell region were immunoreactive for GIRK-2

(Fig. 6E-G). 


\section{Discussion}

In the present study, we established a novel system for the quantitative evaluation of dopaminergic neurite outgrowth. Mesencephalic cells were plated within an isolation wall and the distance between dopaminergic growth cones and the mesencephalic cell region was measured as dopaminergic neurite length. When the striatal cell region was laid adjacent to the mesencephalic cell region, dopaminergic neurites preferentially innervated the striatal cells.

Dopaminergic fibers extend not caudally, but rostrally in vivo. It is noteworthy that dopaminergic neurite outgrowth was promoted by striatal cells, but not spinal cells. Furthermore, we have been able to show that dopaminergic axons formed synapses with striatal neurons. These findings indicate that the new system using primary dissociated neruons reflects the features of dopaminergic axonal projections in vivo. This preference for the striatum was observed in a previous report using co-cultures of mesencephalic slices and striatal or cortical slices (Becq et al., 1999). The attractive effect of striatal cells could be explained by striatum-derived diffusible factors (Hernández-montiel et al., 2008) and/or adhesion molecules (Deschamps et al., 2009). Interestingly, in the case of spinal cells, dopaminergic neurite outgrowth was suppressed. This finding indicates that spinal cells express repulsive factors for extending dopaminergic axons. Semaphorin 3F inhibits dopaminergic neurite outgrowth and guides neurites rostrally (Yamauchi et al., 2009). Semaphorin 3F expression at embryonic stages is higher in the spinal cord than in the telencephalon (Kusy et al., 
2003). Therefore, one of the candidates for the repulsive factors may be semaphorin $3 \mathrm{~F}$, although

further investigation is needed.

In vitro models using dissociated cells are useful for the quantitative evaluation of neurite

outgrowth and analysis of molecular mechanisms. Our system has several advantages over classical

methods for the evaluation of neurite outgrowth. In general, quantitative assessments of neurite

outgrowth are performed by measuring the length of the longest neurite, total neurite length, average

neurite length, or the length of segments without distinguishing between axons and dendrites (Radio

and Mundy, 2008). Although the longest neurite is sometimes presumed to be an axon (Kern and

Audesirk, 1995), almost all growth cones extending from the mesencephalic cell region were axons

in our system. Therefore, we could specifically assess axonal elongation. It has been reported that an anti-pNF antibody (SMI31) used as a marker with the axon used in this study recognized the nuclei of fetal neurons and glia cells besides axons (Schilling et al. 1989). Hence, it is thought that the nuclei observed in Fig. 2E belong to glia cells infiltrating from the mesencephalic cell region. In addition, cell density is critical to the accurate quantification of dopaminergic neurite length in primary mesencephalic cultures. A low cell density might make it easier to identify individual neurites, but primary dopaminergic neurons tend to die at low density (Consales et al., 2007). To solve this problem, immature dopaminergic neurites are generally measured in the early stages of cultivation before individual neurites become indistinguishable (Macé et al., 2002; Pedersen et al., 
2004; Sotogaku et al., 2007). On the other hand, in our system, primary mesencephalic cells were cultured for 11 days at high cell density. Therefore, this procedure is suitable for quantifying the length of mature dopaminergic axons.

In this study, we demonstrated that dissociated dopaminergic neurons preferentially extended their axons to striatal cells, and formed synapses with striatal neurons. Hence, it is thought that this system can be relied on as a good in vitro model of in vivo development. Our quantitative method might be useful for elucidating the molecular mechanisms responsible for dopaminergic axonal projections and for optimizing the regeneration of nigrostriatal projections. 


\section{Acknowledgements}

This work was supported by grants-in-aid for Scientific Research from the Japan Society for the

Promotion of Science and from the Ministry of Education, Culture, Sports, Science and Technology

of Japan. We thank our colleagues for helpful discussions. 


\section{References}

Becq H, Bosler O, Geffard M, Enjalbert A, Herman JP. Anatomical and functional reconstruction of the nigrostriatal system in vitro: selective innervation of the striatum by dopaminergic neurons. J. Neurosci. Res., 1999;58:553-66.

Consales C, Volpicelli F, Greco D, Leone L, Colucci-D'Amato L, Perrone-Capano C, di Porzio U. GDNF signaling in embryonic midbrain neurons in vitro. Brain. Res., 2007;1159:28-39.

Cooper MA, Kobayashi K, Zhou R. Ephrin-A5 regulates the formation of the ascending midbrain dopaminergic pathways. Dev. Neurobiol., 2009;69:36-46.

Deschamps C, Faideau M, Jaber M, Gaillard A, Prestoz L. Expression of ephrinA5 during development and potential involvement in the guidance of the mesostriatal pathway. Exp.

Neurol. 2009;219:466-80.

Gaillard A, Decressac M, Frappé I, Fernagut PO, Prestoz L, Besnard S, Jaber M. Anatomical and functional reconstruction of the nigrostriatal pathway by intranigral transplants. Neurobiol Dis. 2009;35:477-88.

Gates MA, Coupe VM, Torres EM, Fricker-Gates RA, Dunnett SB. Spatially and temporally restricted chemoattractive and chemorepulsive cues direct the formation of the nigro-striatal circuit. Eur J Neurosci. 2004:19:831-44.

Hernández-Montiel HL, Tamariz E, Sandoval-Minero MT, Varela-Echavarría A. Semaphorins 3A, 
3C, and 3F in mesencephalic dopaminergic axon pathfinding. J Comp Neurol.

2008;506:387-97.

Izumi Y, Yamamoto N, Matsuo T, Wakita S, Takeuchi H, Kume T, Katsuki H, Sawada H, Akaike

A. Vulnerability to glutamate toxicity of dopaminergic neurons is dependent on endogenous

dopamine and MAPK activation. J. Neurochem., 2009;110:745-55.

Katsuki H, Tomita M, Takenaka C, Shirakawa H, Shimazu S, Ibi M, Kume T, Kaneko S, Akaike

A. Superoxide dismutase activity in organotypic midbrain-striatum co-cultures is associated

with resistance of dopaminergic neurons to excitotoxicity. J. Neurochem., 2001;76:1336-45.

Kern M. \& Audesirk G. Inorganic lead may inhibit neurite development in cultured rat

hippocampal neurons through hyperphosphorylation. Toxicol. Appl. Pharmacol., $1995 ; 134: 111-23$.

Kirik D, Rosenblad C, Bjorklund A, Mandel RJ. Long-term rAAV-mediated gene transfer of GDNF in the rat Parkinson's model: intrastriatal but not intranigral transduction promotes functional regeneration in the lesioned nigrostriatal system. J. Neurosci., 2000;20:4686-700.

Kusy S, Funkelstein L, Bourgais D, Drabkin H, Rougon G, Roche J, Castellani V. Redundant functions but temporal and regional regulation of two alternatively spliced isoforms of semaphorin 3F in the nervous system. Mol. Cell. Neurosci., 2003;24:409-18. 
Lin LF, Doherty DH, Lile JD, Bektesh S, Collins F. GDNF: a glial cell line-derived neurotrophic factor for midbrain dopaminergic neurons. Science, 1993;260:1072-73.

Macé K, Saxod R, Feuerstein C, Sadoul R, Hemming FJ. Chondroitin and keratan sulfates have opposing effects on attachment and outgrowth of ventral mesencephalic explants in culture. J. Neurosci. Res., 2002;70:46-56.

Maeda T, Ibi M, Shimazu S, Akaike A. Co-culture with the striatum attenuates $\mathrm{N}$-methyl-D-aspartate cytotoxicity in dopaminergic neurons of rat mesencephalic slice cultures. Jpn. J. Pharmacol., 1998;77:161-7.

Nakamura S, Ito Y, Shirasaki R, Murakami F. Local directional cues control growth polarity of dopaminergic axons along the rostrocaudal axis. J. Neurosci., 2000;20:4112-9.

Østergaard K, Jones SA, Hyman C, Zimmer J. Effects of donor age and brain-derived neurotrophic factor on the survival of dopaminergic neurons and axonal growth in postnatal rat nigrostriatal cocultures. Exp. Neurol., 1996;142:340-50.

Pedersen MV, Køhler LB, Ditlevsen DK, Li S, Berezin V, Bock E. Neuritogenic and Survival-Promoting Effects of the P2 Peptide Derived From a Homophilic Binding Site in the Neural Cell Adhesion Molecule. J. Neurosci. Res., 2004;75:55-65.

Radio NM. \& Mundy WR. Developmental neurotoxicity testing in vitro: models for assessing 
chemical effects on neurite outgrowth. Neurotoxicology, 2008;29:361-76.

Redmond DE Jr, Elsworth JD, Roth RH, Leranth C, Collier TJ, Blanchard B, Bjugstad KB,

Samulski RJ, Aebischer P, Sladek JR Jr. Embryonic substantia nigra grafts in the

mesencephalon send neurites to the host striatum in non-human primate after overexpression of

GDNF. J. Comp. Neurol., 2009;515:31-40

Schilling K, Duvernoy C, Keck S, Pilgrim C. Detection and partial characterization of a developmentally regulated nuclear antigen in neural cells in vitro and in vivo. J. Histochem.

Cytochem., 1989;37:241-7.

Sotogaku N, Tully SE, Gama CI, Higashi H, Tanaka M, Hsieh-Wilson LC, Nishi A. Activation of phospholipase $\mathrm{C}$ pathways by a synthetic chondroitin sulfate-E tetrasaccharide promotes neurite outgrowth of dopaminergic neurons. J. Neurochem., 2007;103:749-60.

Thompson LH, Grealish S, Kirik D, Björklund A. Reconstruction of the nigrostriatal dopamine pathway in the adult mouse brain. Eur. J. Neurosci., 2009;30:625-38.

Yamauchi K, Mizushima S, Tamada A, Yamamoto N, Takashima S, Murakami F. FGF8 signaling regulates growth of midbrain dopaminergic axons by inducing semaphorin 3F. J. Neurosci., 2009;29:4044-55.

Yue Y, Widmer DA, Halladay AK, Cerretti DP, Wagner GC, Dreyer JL, Zhou R. Specification of 
distinct dopaminergic neural pathways: roles of the Eph family receptor EphB1 and ligand ephrin-B2. J. Neurosci., 1999;19:2090-101. 


\section{Figure legends}

Fig. 1 Measurement of dopaminergic neurite length. A: A polyethylenimine-coated coverslip in a 35 mm culture dish divided into two compartments by a silicone isolation wall. B: Plating of mesencephalic cells derived form rat embryos inside the isolation wall. Mesencephalic cell suspensions $\left(150 \mu \mathrm{L}, 3.0 \times 10^{5}\right.$ cells $\left./ \mathrm{cm}^{2}\right)$ were plated inside the isolation wall. C: A microphotograph of mesencephalic cells in the vicinity of the borderline just after the isolation wall was removed. The isolation wall was removed $24 \mathrm{~h}$ after plating. Upper regions were mesencephalic cells. D: Dopaminergic neurons identified by immunocytochemistry for TH at 12 DIV. An open arrowhead indicates a dopaminergic soma which was located in the most lateral mesencephalic cell region. The dotted line represents the borderline of the mesencephalic cell region. Lengths of arrows show the distances of dopaminergic growth cones from the borderline. Scale bar: $200 \mu \mathrm{m}$.

Fig. 2 Characterization of dopaminergic neurites. A: A representative photograph of immunocytochemistry for TH. Cells were cultured for 11 days and processed for immunocytochemistry. The dotted line shows the borderline. Scale bar: $200 \mu \mathrm{m}$. B: Distribution of dopaminergic growth cones from the borderline. (C-F) Immunocytochemistry of dendritic and axonal markers. The cells were processed for immunostaining of TH, MAP2, NF and GAP43 at 12 DIV. Representative photographs near to (C) and away from (D-F) the borderline. Scale bar: $50 \mu \mathrm{m}$. 
Fig. 3 Effect of GDNF on dopaminergic neurite outgrowth. A: Representative photographs of GDNF -induced dopaminergic neurite outgrowth. Cells were cultured for 10 days in the presence or absence of GDNF (10 ng/mL) and processed for immunostaining of TH. Left; control. Right; GDNF (10 $\mathrm{ng} / \mathrm{mlL}$ ). Dotted lines show the borderline. Scale bar: $200 \mu \mathrm{m}$. B: Distribution of dopaminergic growth cones from the borderline in GDNF-treated cultures. (C-D): Effects of GDNF on the sum of dopaminergic neurite lengths in cultures from E16 (C) and E14 (D) rats. Cells were cultured for 10 days in the presence or absence of GDNF $(1-10 \mathrm{ng} / \mathrm{mL}) . * * p<0.01,{ }^{* * *} p<0.001$ vs. mesencephalic cells only (control).

Fig. 4 Plating of striatal or spinal cells outside of the mesencephalic cell region. A: Mesencephalic cell suspensions $\left(150 \mu \mathrm{L}, 3.0 \times 10^{5} \mathrm{cells} / \mathrm{cm}^{2}\right)$ were plated inside the isolation wall. Striatal or spinal cell suspensions $\left(1.5 \mathrm{~mL}, 3.0 \times 10^{5}\right.$ cells $\left./ \mathrm{cm}^{2}\right)$ were plated outside of the isolation wall. (B-C):

Microphotographs of the vicinity of the borderline just after the isolation wall was removed. The isolation wall was removed $24 \mathrm{~h}$ after plating. Upper regions were mesencephalic (M) cells. Lower regions were striatal (St; B) and spinal (Sp;C) cells. Scale bar: $200 \mu \mathrm{m}$.

Fig. 5 Effects of striatal and spinal cells on dopaminergic neurite outgrowth. A-B: Representative 
photographs of dopaminergic neurite outgrowth in paired-cultures of mesencephalic and striatal (A) or spinal (B) cells from E16 rats. Mesencephalic cells were paired-cultured with striatal or spinal cells $\left(3.0 \times 10^{5} \mathrm{cells} / \mathrm{cm}^{2}\right)$ for 10 days and processed for immunostaining of TH. Dotted lines show the borderline. The upper region from the borderline shows the mesencephalic cell region, and the lower region shows the striatal or spinal cell region. Scale bar: $200 \mu \mathrm{m}$. (C-D): Distribution of dopaminergic growth cones from the borderline in paired-cultures with striatal (C) and spinal (D) cells from E16 rats. (E-F): Effects of striatal (E) and spinal (F) cells from E16 rats on the sum of dopaminergic neurite lengths. $(\mathrm{G}-\mathrm{H})$; Effects of striatal $(\mathrm{G})$ and spinal $(\mathrm{H})$ cells from E14 rats on the sum of dopaminergic neurite lengths. Striatal $\left(\mathrm{St} ; 0.75-3.0 \times 10^{5} \mathrm{cells} / \mathrm{cm}^{2}\right)$ or spinal $\left(\mathrm{Sp} ; 1.5-3.0 \times 10^{5}\right.$ cells $/ \mathrm{cm}^{2}$ ) cells were plated outside of the mesencephalic cell region. Mesencephalic and striatal cells were pair-cultured for 10 days. $* * p<0.01, * * * p<0.001$ vs. mesencephalic cells only (control).

Fig. 6 Representative confocal images of dopaminergic axons extending to the striatal cell region.

(A-D): Synapse formation of dopaminergic axons with striatal neurons. Mesencephalic cells were paired-cultured with striatal cells for 10 days, and the cells were processed for immunostaining of TH (A; dopaminergic axon) and synaptophysin (B; presynapse). A merged image is also shown (C). A magnified view of the area enclosed by the white square is shown in the right panel (D). (E-G): Innervation of striatal cells by dopaminergic neurons derived from the substantia nigra pars 
compacta. Mesencephalic cells were paired-cultured with striatal cells for 10 days, and the cells were processed for immunostaining of TH (E) and GIRK-2 (F). A merged image is also shown (G). An arrowhead indicates a representative double-stained axon. 
F:

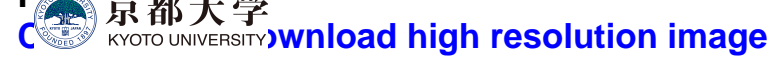
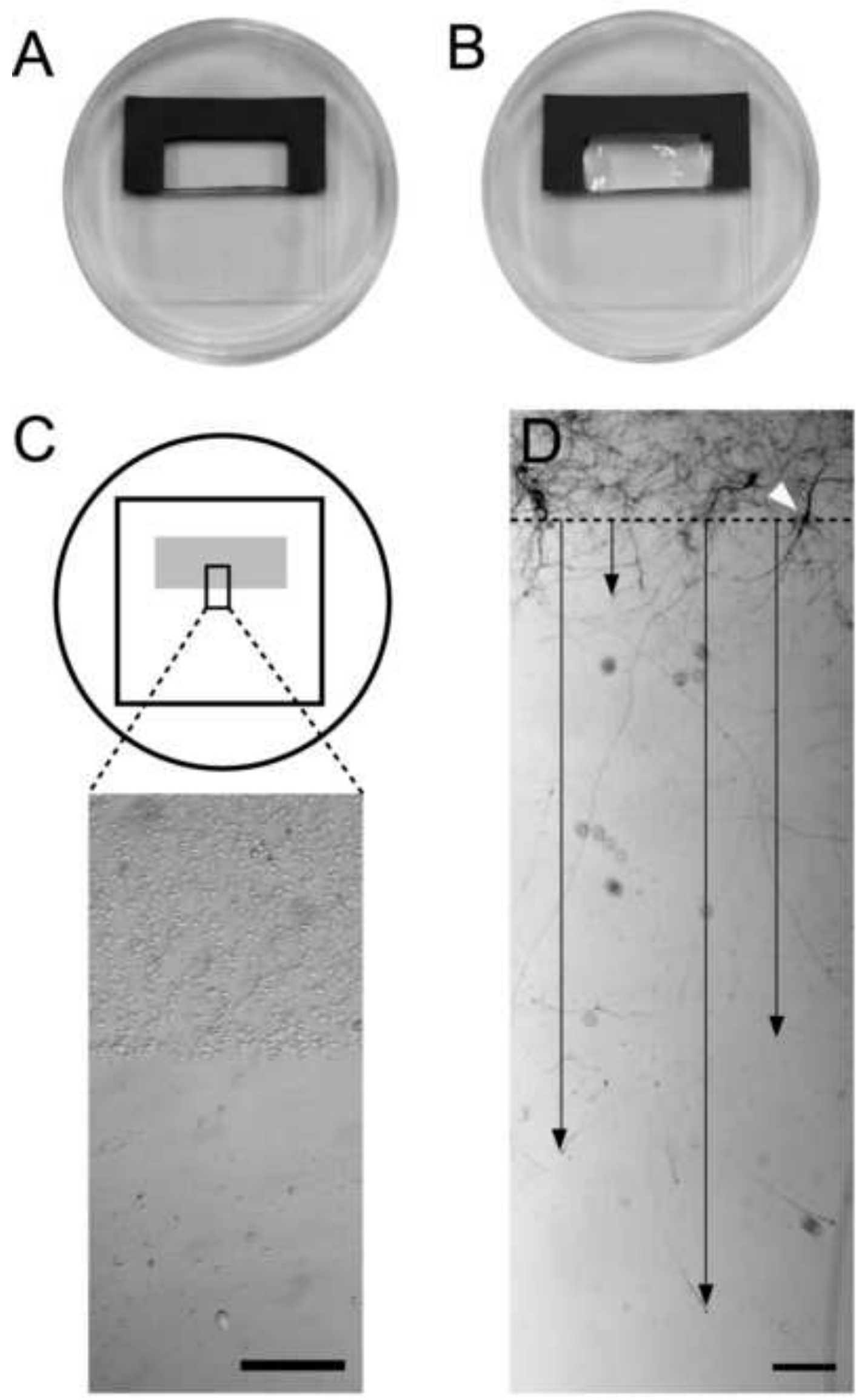

Figure 1 Wakita et al. 

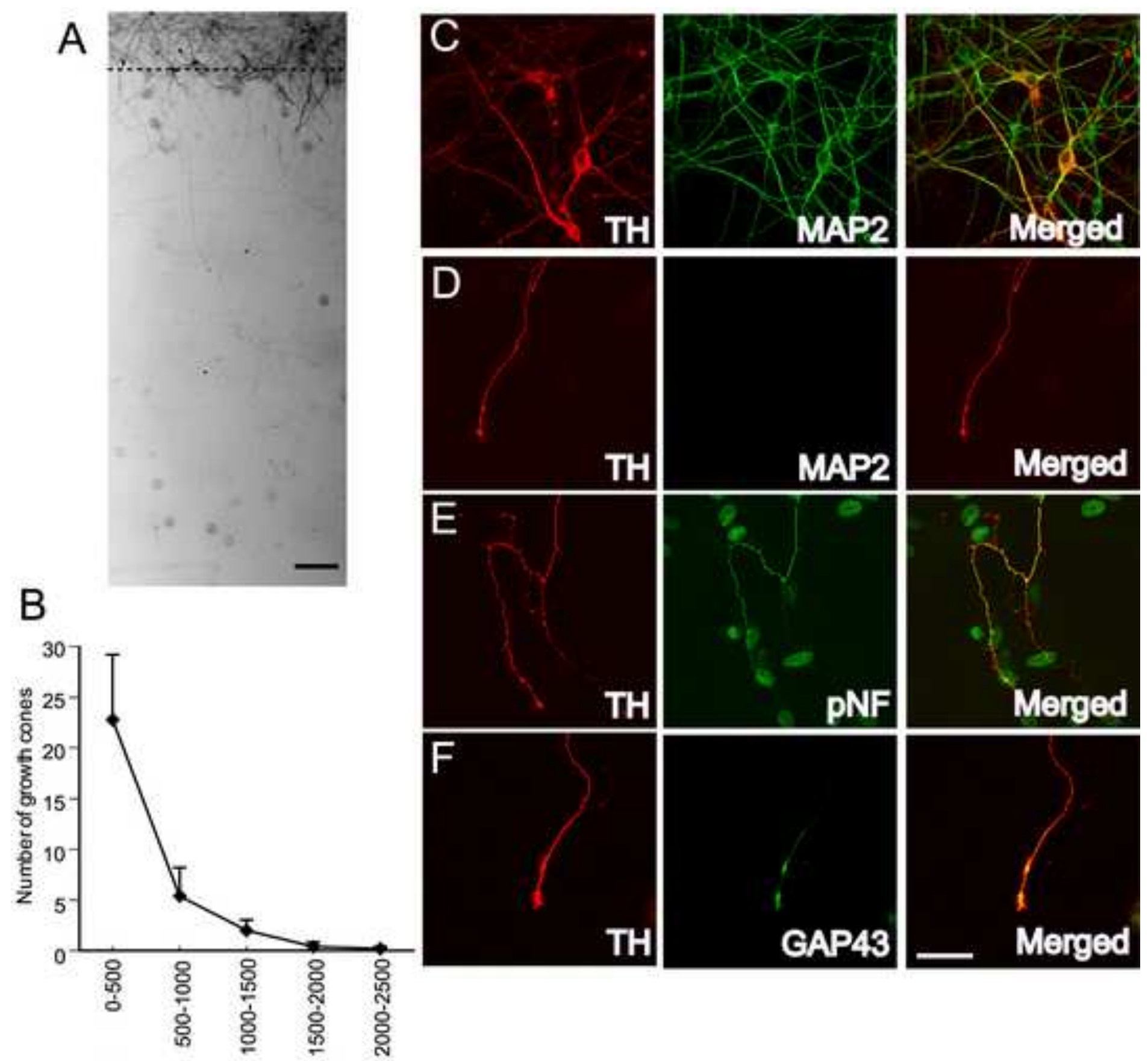

Distance from borderline $(\mu \mathrm{m})$

\section{Figure 2 Wakita et al.}



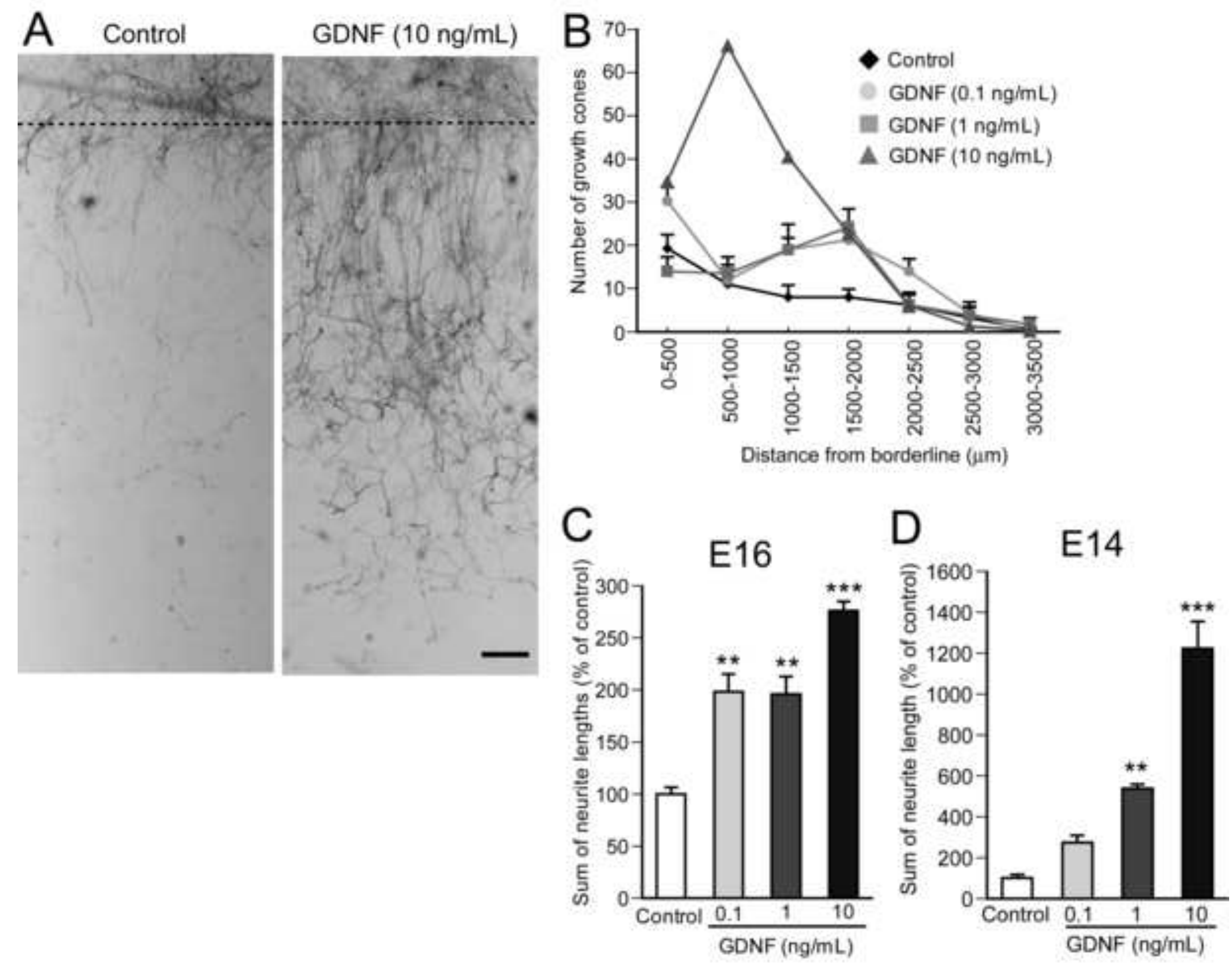

\section{Figure 3 Wakita et al.}




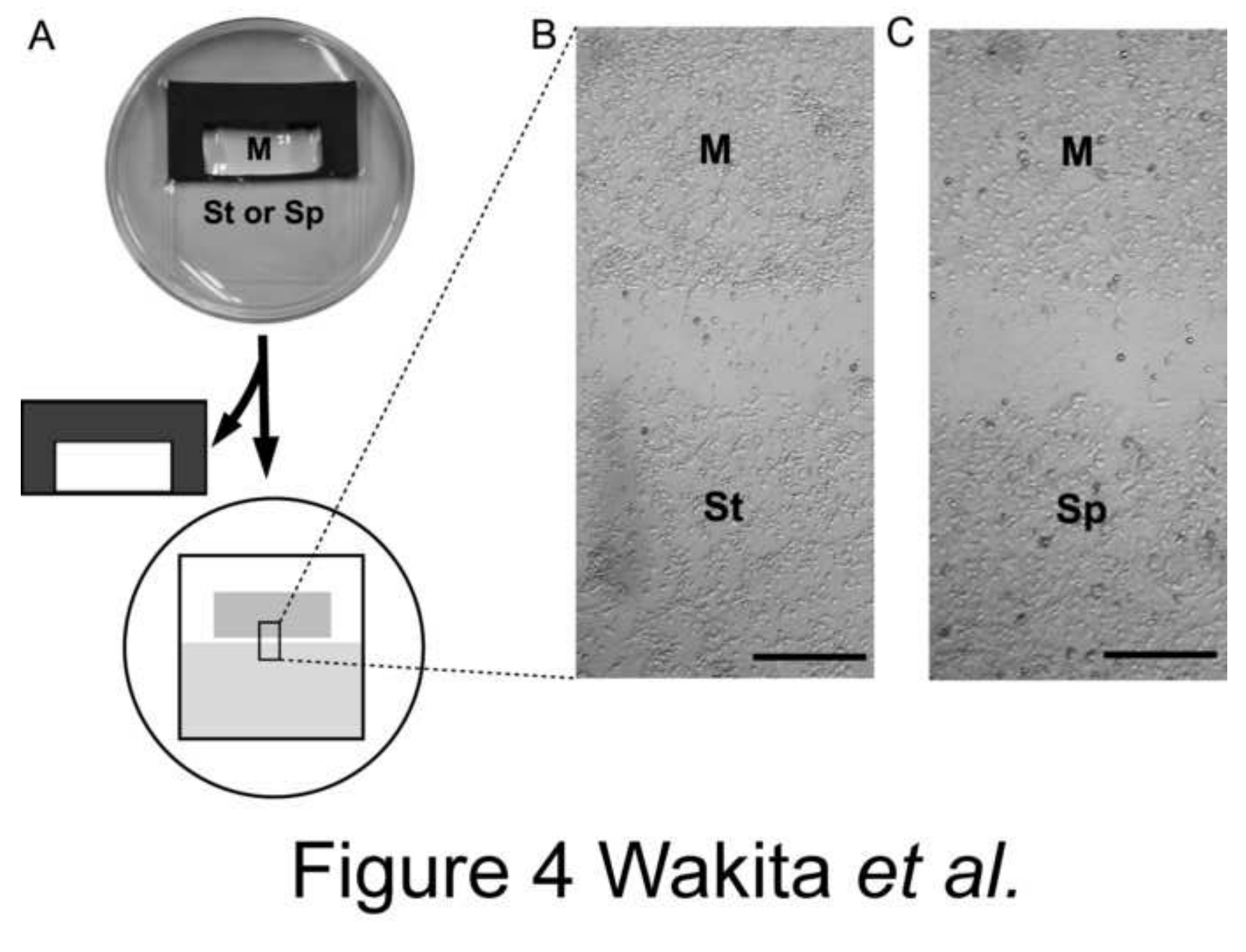

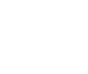
.

\section{to download high resolution image}

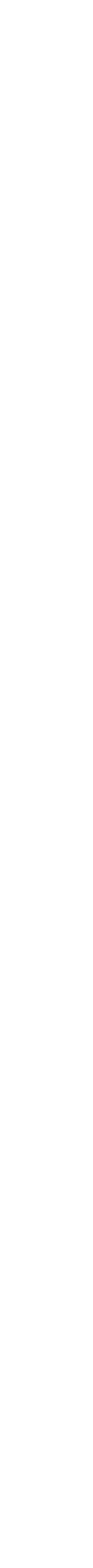

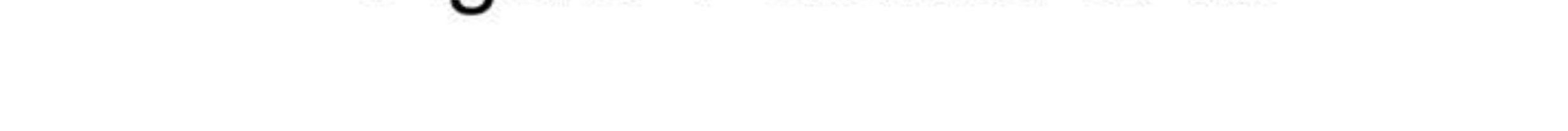




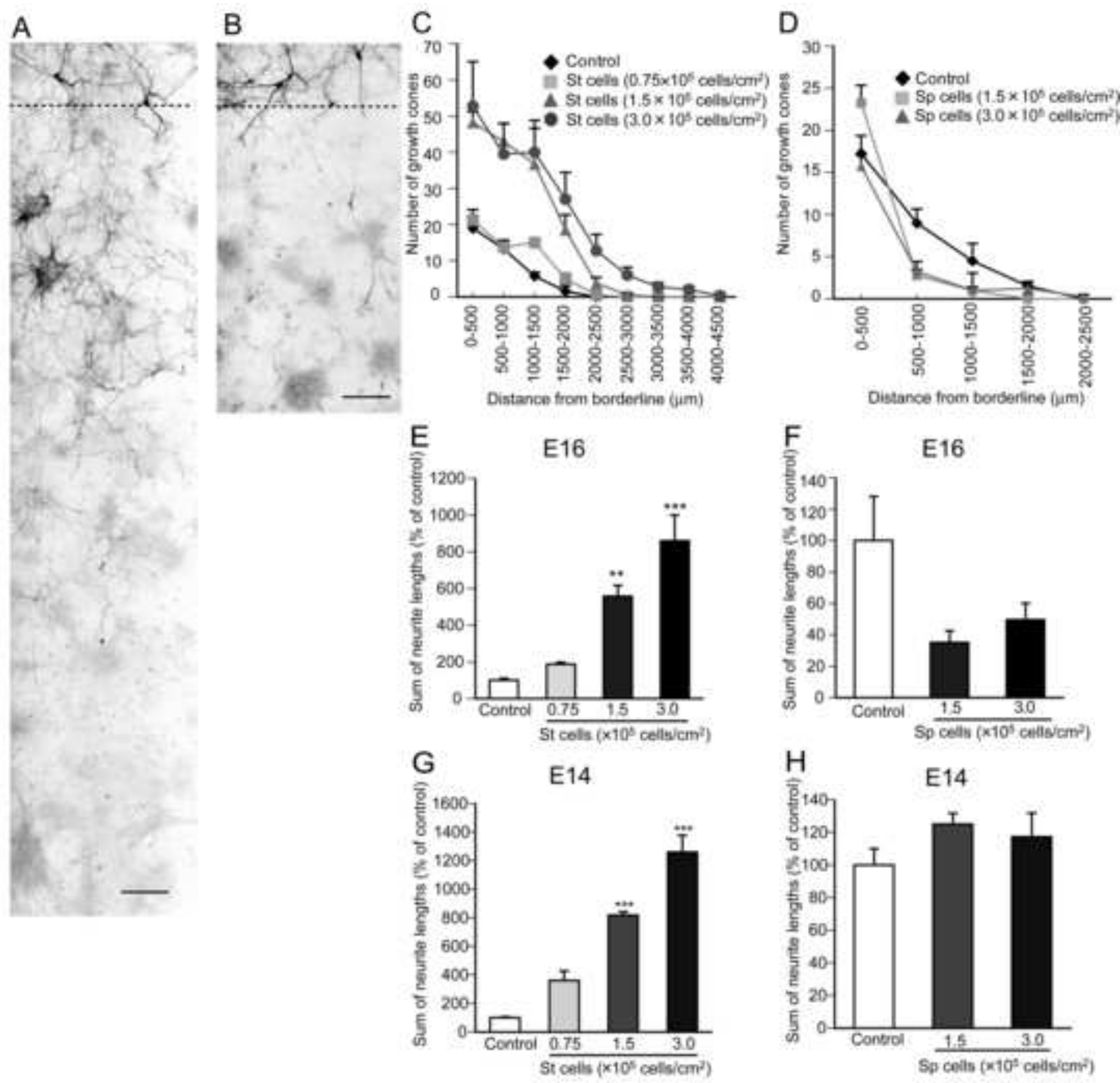

Figure 5 Wakita et al. 

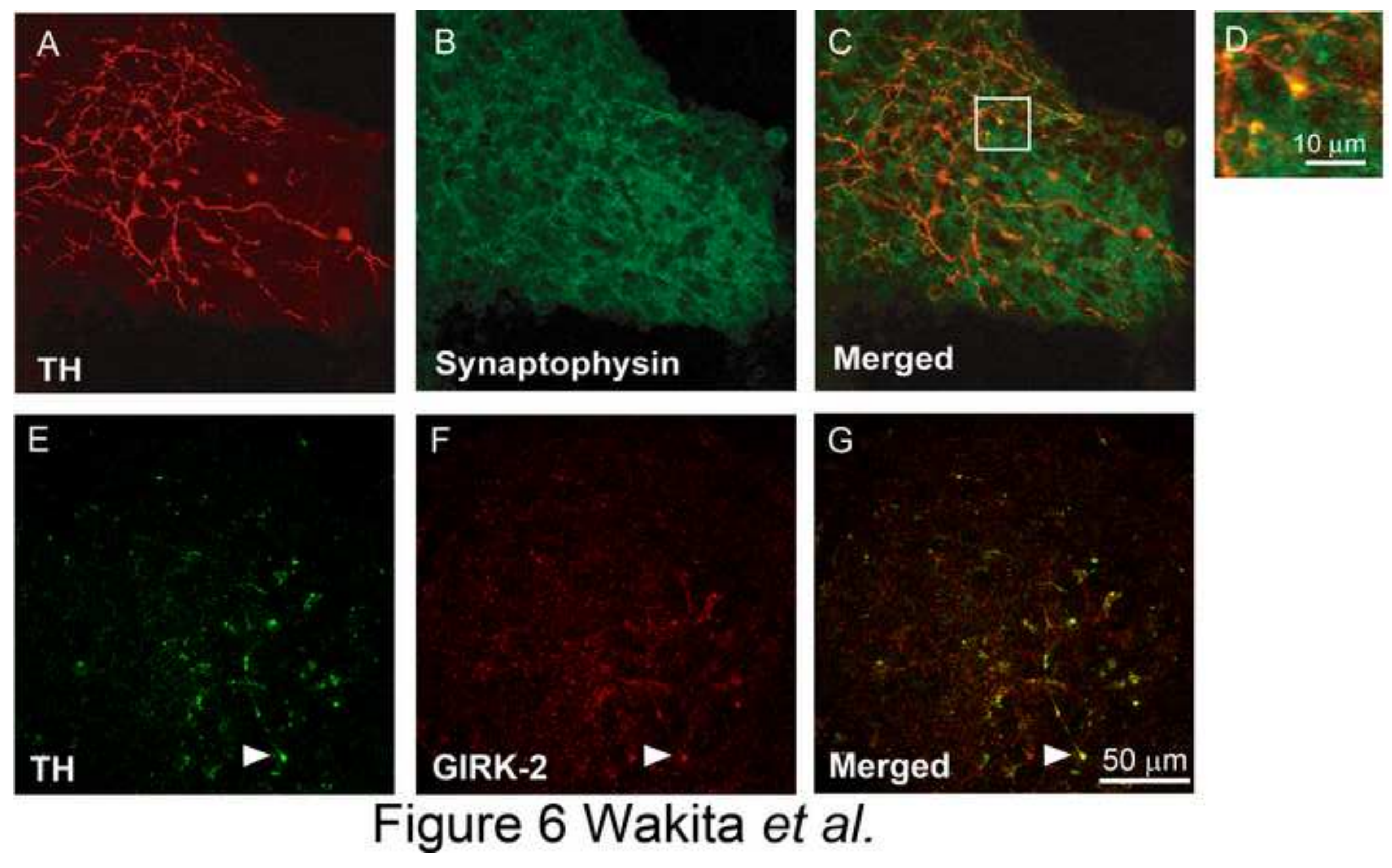

Figure 6 Wakita et al.

GIRK-2 $\longrightarrow \quad$ Merged $>50 \mu \mathrm{m}$

$F$

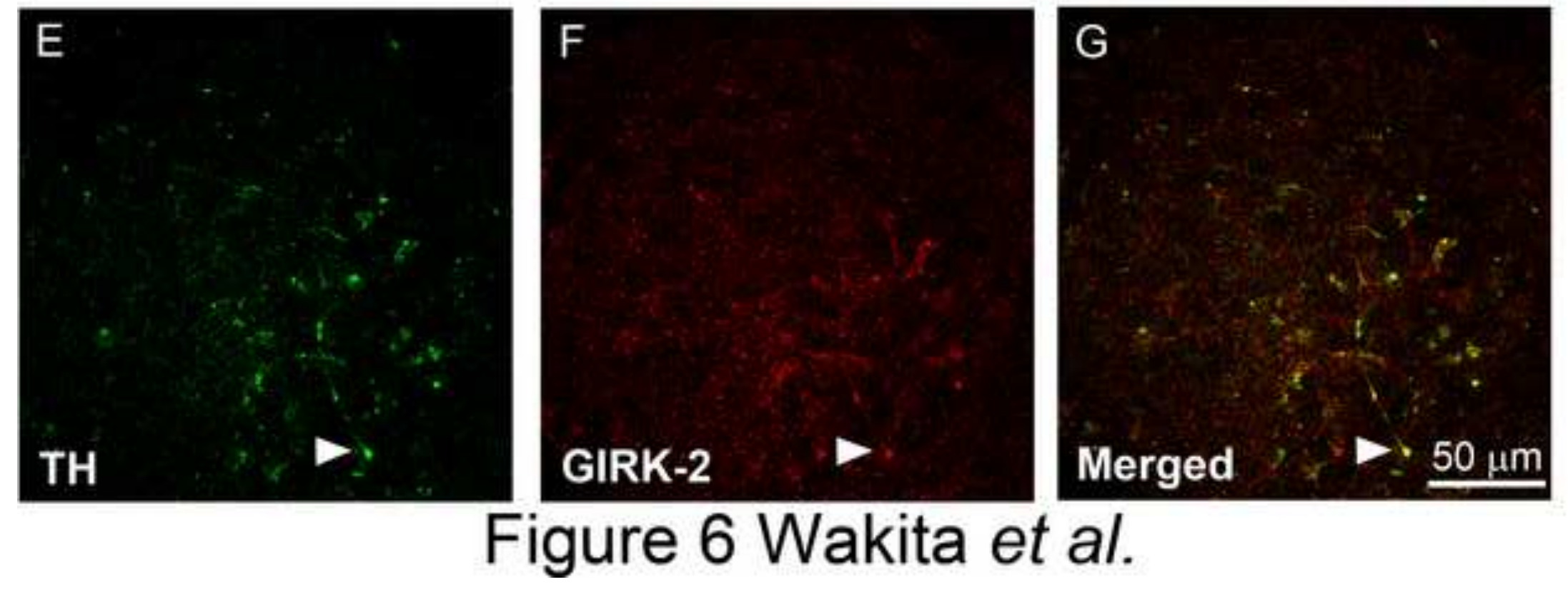

$$
\text { (n) }
$$
Click here to download high resolution image 